\title{
An Analysis of Climate Impact on Landscape Design
}

\author{
Xuepeishan Chen \\ School of Architecture, Planning \& Landscape, Newcastle University, Newcastle upon Tyne, UK \\ Email:mlbsabc@sina.com
}

Received 17 June 2016; accepted 22 July 2016; published 25 July 2016

Copyright @ 2016 by author and Scientific Research Publishing Inc.

This work is licensed under the Creative Commons Attribution International License (CC BY).

http://creativecommons.org/licenses/by/4.0/

(c) (i) Open Access

\begin{abstract}
According to the severe climate change in recent days, professionals among different fields now pay more attention to the management and adjustment when meeting the issues of climate. Moreover, climate also obviously affects the natural and designed landscape. To systematically and specifically understand how landscape is designed in response to different climate, this paper will firstly discuss the fundamental interaction between landscape design and climate. And then it will evaluate the different landscape elements dealing with different types of climate, finally and importantly to analysis the definite impact on practical landscape design based on former findings. The result will focus on the decision making on design methods within climate change and provide rational recommendations for designers and planning of future landscape design.
\end{abstract}

\section{Keywords}

Landscape Design, Climate, Landscape Factors, Material

\section{Introduction}

The climate is the basis for human survival, and it provides necessary conditions for human survival. Sunshine, rain and soil form a natural foundation. People have formed their own way of life according to the climate conditions in different areas. Climate plays an important role in people's life, and the climate is the basis of all planning and design. If the planning and design of the ultimate aim is to meet the needs of the people in the environment, the climate must first be considered.

Climate change has important effect on human and natural systems. For all countries, extreme weather, climate events and frequency of weather disasters increase. The impact of climate change on water resources is also critically debated, and global warming accelerates the speed of water cycle process and increases uneven spatial precipitation [1]. The latest report of United Nations Intergovernmental Panel on Climate Change special 
committee (IPCC) shows that climate warming allows all doubt. Thus it is necessary for the paper to systematically defined the impact of climate change on landscape and to study landscape design combined with recent studies from predecessors revealing that landscape environment factors affect assessment of thermal comfort from the research, which ultimately response to the different landscape elements in different design dimension.

\section{Landscape and Landscape Design}

Landscape refers to the synthesis of scenery, mountains, rivers, topography, geomorphology, etc. land and land on the matter and space composed of natural and anthropogenic activities. It reflects the comprehensive characteristics of a particular region [2].

Landscape design reflects the complex historical traditions, customs, geographical features and city development and other non natural landscape. The concept of landscape on the interpretation of many of the modern landscape architecture defined landscape is a complex concept, broad. Also, the landscape involved, with the continuous development of the times in the renewal and expansion. With the rapid development of science and technology and the economy today, people pay more and more attention to the environment, and more scientific and objective awareness and understanding of landscape environment [3]. There is a discipline, however, imposed on this complexity. The revolution of the globe gives the heartbeat of day and night which regulates the activities and reposes of natural life [4].

First, landscape which is based on the earth's surface environment complex, directs the performance of natural landscape, including climate, geography, hydrology and other factors. This is the most basic elements of the regional environment [5]. At the same time, along with the human factors involved, people built buildings, streets, landscape began to highlight the social attribute [6]. Richard referred to "the landscape is our history and labor and social creativity and feelings of our material record, is constantly personal desire and demand of society struggle records. From this perspective, it is a kind of common concrete language. The landscape is not static, and it is connected with our past and present. It is owned and created, changed, changing power sometimes from nature itself.

\section{Impacts of Climate on Landscape}

This chapter focuses on the influence of climate on landscape space related to the specific factors (topography design, waterscape, vegetation, ground paving and landscape facilities).

\subsection{Impact on Topography Design}

Due to the topography and geographic range, slope and elevation, and direct solar radiation and sky diffuse difference, which make the load on the ground of the solar radiation varies from place to place. One of the most important factors is the direction and height of slope [7]. On the hill to the East and the west can effectively block the sun (see Figure 1). Secondly, the slope surface and the sun angle difference influenced by solar radiation intensity, such as: with the sun light vertical slope surface to receive the maximum amount of radiation.

According to the relevant scholars, less harmful effects of wind slope to the valley 50 - 100 meters high. They are generally located in low-lying areas, the sinking of cold air to form inversion layer, belonging to the Regional Greenhouse Environment better. Due to the cold plateau and cold pit, the top of the hill and slope valley has a poor environment [8]. The tall mountains formed a wet windward slope, leeward slope and small mountains form a wet. In the air meet a tall hill, moist air concentration rises, air reaches the dew point in the windward slope is the formation of cold climate. This makes the leeward drier caused the windward slope of wind and rain, climate phenomenon and leeward slope dry wind [9]. The small mountain is the opposite. Thus, there is the effect of air greenhouse environment on regional terrain elevation. Likewise, in the landscape space, the terrain design can impact on the climate and environment space.

Undulating terrain can significantly change direction near earth atmospheric circulation, bound slope of the temperature difference between hot and cold, forms the regional atmospheric circulation, thus affecting the urban wind environment. This forms the local terrain wind. Local terrain wind is regional climate impact phenomenon, the scale is about level less than $10 \mathrm{~km}$, vertical $1 \mathrm{~km}$. Valley wind usually occurs in the narrow and steep valleys, with the cyclical nature of the diurnal cycle, which belongs to the special places of the wind. 


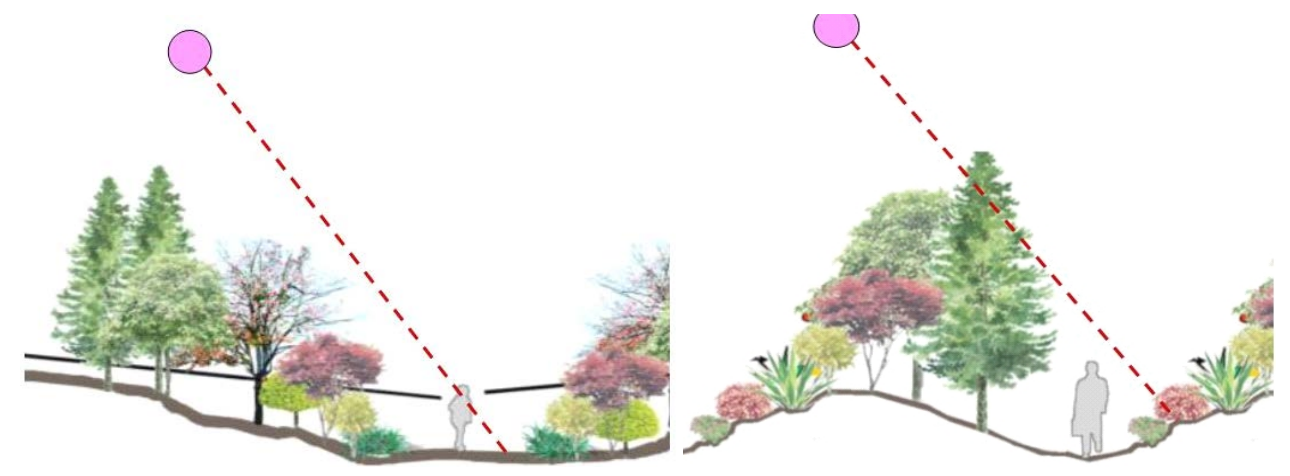

Figure 1. Effect of topography on sunshine (solar incident angle is the same).

Valley wind relatively mild, due to the air at night along the hillside down, to near surface cooling caused, effectively improve under the static wind city regional climate. Such as the geographical environment in some areas surrounded by mountains, the summer villages dominated the wind are different from each other, but in the plain area of law. Through the analysis of different terrain and improve the regional climate, and provide a theoretical basis for the urban landscape design in landscape design in the urban landscape.

To sum up, from the macro level urban landscape of the urban environment, the impact of the urban environment is very important, the same terrain design on the micro level urban landscape space and the role cannot be ignored. To a certain extent, the small terrain in the landscape space can be relatively free of change, so the feasibility of the improvement of the space climate is larger. In the design of terrain landscape space, we should make full use of the transformation of the terrain or, in order to achieve the purpose of regulating the climate.

\subsection{Impact on Waterscape}

Waterscape form of city landscape is generally divided into static and dynamic landscape water landscape. Water landscape is divided into rivers, lakes and ponds, pond and pond etc. [10]. Dynamic water landscape is divided into water, water fountains, water curtain wall, etc. Static water is much larger than the open area of the surface of the water. Open, not only can form enlarged water landscape, and rivers and lakes belongs to natural features, often at 1000 areas, the waters as the wild animals and plants to provide habitat. Dynamic water forms, mainly in water, water fountains, water curtain wall, etc. (see Figure 2, Figure 3) and hydrostatic comparison, water flow due to the contact surface with the air increases, the formation of water mist can more effectively increase the air humidity.

Effect of water on the city air temperature is mainly influenced by three factors. One is because of the surface reflectance, surface reflectance less than the land. Under the same conditions, the surface of the water can absorb more solar heat than the land surface, which makes the surface temperature rise. The related research shows that the climate is dry and the altitude is higher, because the solar radiation is stronger, the surface temperature difference increases, the increase of temperature effect is obvious. And because of the high altitude area of air density and volumetric heat capacity is small, and the warming effect is more obvious.

Followed by the heat capacity of water to more than terrestrial soil and water in heat gain process can store more heat, making over the water heat reduced played a cooling effect. While the water during the cooling period, will release more heat than the land, the water over the heat increased, the warming effect. Research shows that the climate drier region, and as a result of land air moisture and heat capacity less, relatively greater heat conversion between water and land, making temperature effect is more obvious.

Finally, due to the evaporation of water, the air over the water with plenty of water molecules, with the increase of wind frequency, water surface evaporation consumption heat (LKG of evaporation of water can be heat absorption $2412 \mathrm{k}$ ) increased [11]. At the same time, the temperature above the water surface is reduced. The study showed that the climate is relatively dry region, due to the lack of land soil moisture constraints increase, so that the water evaporation caused by the reduction of temperature effect is more obvious.

To sum up, climate has an important impact on water environment. According to the related research also shows that under the same external conditions, running the fountain prompted water molecules with air heat exchange, to reduce the effect of air temperature, air temperature by water show obvious difference [12]. Let the 


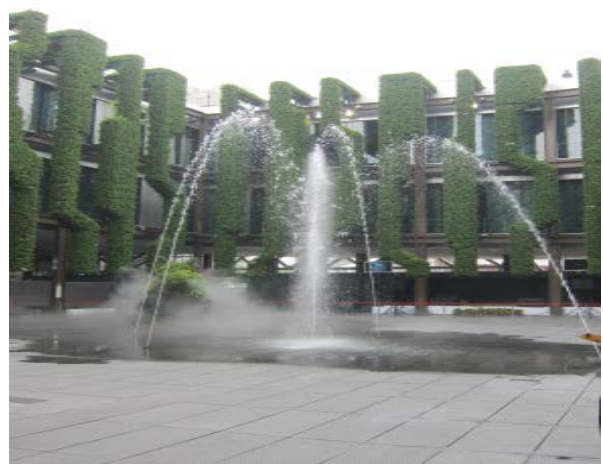

Figure 2. Fountain.

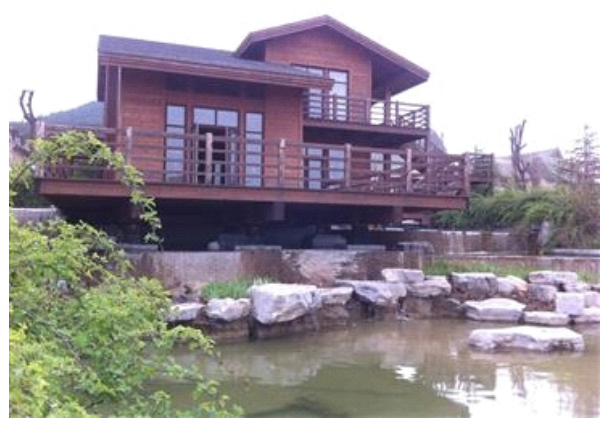

Figure 3. Running water.

hot space to cool down, effectively increase the comfort of the human body. With the evaporation of water, the influence of water on the air temperature in the city is accompanied with the humidity effect. Recent studies revealed that outdoor thermal environment factors, including air temperature, wind speed, relative humidity and solar radiation, affect assessment of thermal comfort, e.g., thermal perception and satisfaction [13]. However, the differences in the comfort of people in different spatial climates are different (see Table 1). The humidity level influence how temperatures are felt. High humidity reduces the comfortable maximum temperature; low humidity allows a tolerance for higher temperature. At the lower limit of the comfort level humidity has little influence for individual perception and satisfaction which could be applied in material selection.

Relatively dry climate in the public space in the water features, in order to meet the beauty of the landscape at the same time, it can improve the effectiveness of regional climate and the balance of air humidity. Relative to the area of cold winter and hot summer, the annual average relative humidity is up to $70 \%-80 \%$. In contrast, the effect of the water body on the air humidification and cooling effect is not applicable. Therefore, the use of water to improve the air temperature effect should be adapted to local conditions to make water features design [14].

\subsection{Impact on the Pavement}

To response to the cooling effect of trees, the use of high albedo materials can reduce absorption of solar radiation through urban ground surface and building envelopes and keep their surfaces cooler [15]. Classification of pavement is more, this paper mainly based on the material and texture which are different, divided into hard pavement and soft pavement.

Hard surfacing refers to the processing of natural building materials, such as natural stone, wood or cement prefabricated blocks and other types of artificial building materials. According to the material and texture, it can be divided into stone, wood, brick and wood, concrete, gravel, pebbles, wood and other recycled materials (see Figure 4). Stone is the most widely used material in paving materials. There are more types of stone, natural texture of the limestone, the layered conglomerate and the color of the bright color of the granite. In the landscape 

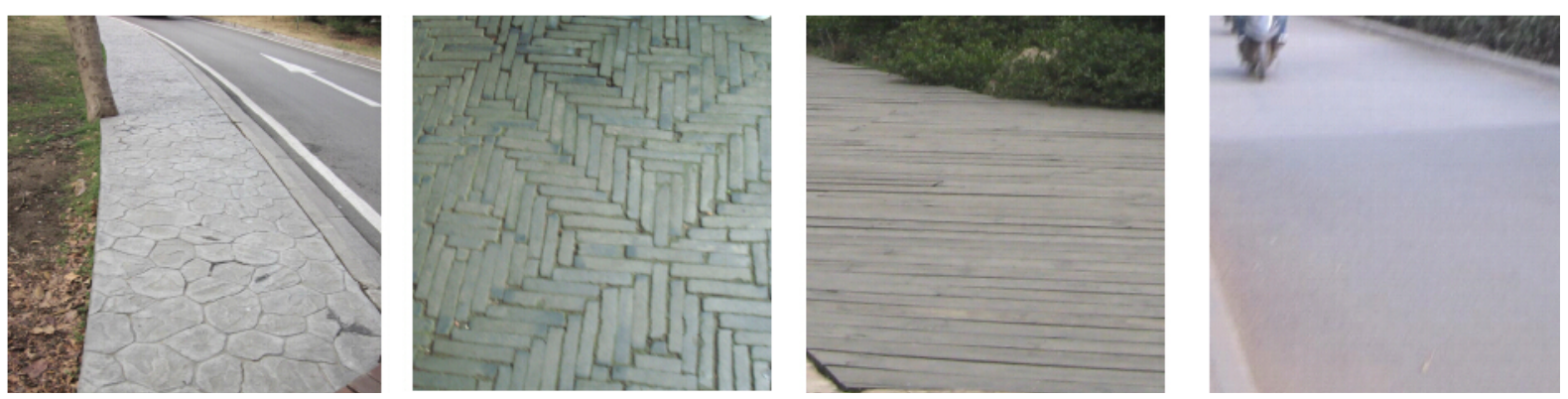

Figure 4. Cement pavement; paving bricks; wood pavement; concrete pavement.

Table 1. Humidity and comfortable temperature.

\begin{tabular}{ccc}
\hline Humidity $(\%)$ & Daytime temperature $\left({ }^{\circ} \mathrm{C}\right)$ with solar radiation & Temperature at night $\left({ }^{\circ} \mathrm{C}\right)$ without solar radiation \\
\hline $0-30$ & $22-30$ & $20-27$ \\
$30-50$ & $22-29$ & $20-26$ \\
$50-70$ & $22-28$ & $20-26$ \\
$70-100$ & $22-27$ & $20-25$ \\
\hline
\end{tabular}

design can form a rich and colorful landscape effect.

The relative affinity of wood is strong, which gives a natural and comfortable feeling to the human. Wood, in addition to the traditional wooden platform and pavilion gallery use, can also be wood waste wood, bark and other paved to the edge of the sidewalk or tree pool planting pool [16]. This can achieve the coverage of bare soil, is conducive to the soil moisture and absorb rain and other ecological environmental protection effect, is an excellent water permeability material.

\section{Further Impact on Landscape Design}

Landscape design materials have a great impact on the comfort of space weather. Through the people of different material landscape pavilion use of the survey and analysis: In summer, the vast majority of people tend to stay in the shade of the landscape facilities. And in winter, people tend to stay in the light of the landscape pavilion. According to the relevant research shows that the different shading methods, the solar radiation has a significant impact [17].

According to the different needs of the sun, the reasonable selection of landscape facilities and materials, the climate of the landscape space has a moderating effect. Non transparent material of the landscape pavilion, can effectively block the summer heat of the sun, but cannot guarantee the effective use of the winter sun [18]. And transparent glass or other material landscape pavilion, which can ensure almost all of the solar radiation through the pavilion on the top surface of, can obviously improve the temperature of the space inside the pavilion (see Figure 5). Although the winter to ensure the sun's demand, but it consider the summer heat of the sun. Need to combine the design of green planting trees collocation, to summer sun, the double effect of winter light.

Landscape facilities can be separated by space, blocking air flow in the air, so as to achieve the effect of landscape space stroke environment compared to the simple landscape facilities, the impact of space on the wind, combined with the common role of green planting design and landscape facilities, can increase the impact on the space between the stroke environment. The plant itself has certain closeness, can play the role of the wind screen in the landscape space, and dense plants can be achieved to reduce the wind speed of 75\% - 85\% [19].

In summer, the main demand for human comfort in the environment is to decrease the temperature and increase the humidity. Pavement materials should be low heat absorbing materials, to reduce the absorption of solar radiation. At the same time, it has the function of considering the material with low reflectivity, which can reduce the temperature of space environment (see Figure 6). Because of the relatively high absorption rate and reflectivity of the concrete to the solar radiation, it should avoid the use of large area or through the planting of green combination design, to achieve the purpose of cooling. Grassland has the advantage of low reflectivity and absorbing solar radiation, in the design of the ground pavement, can be combined with embedded grass, 

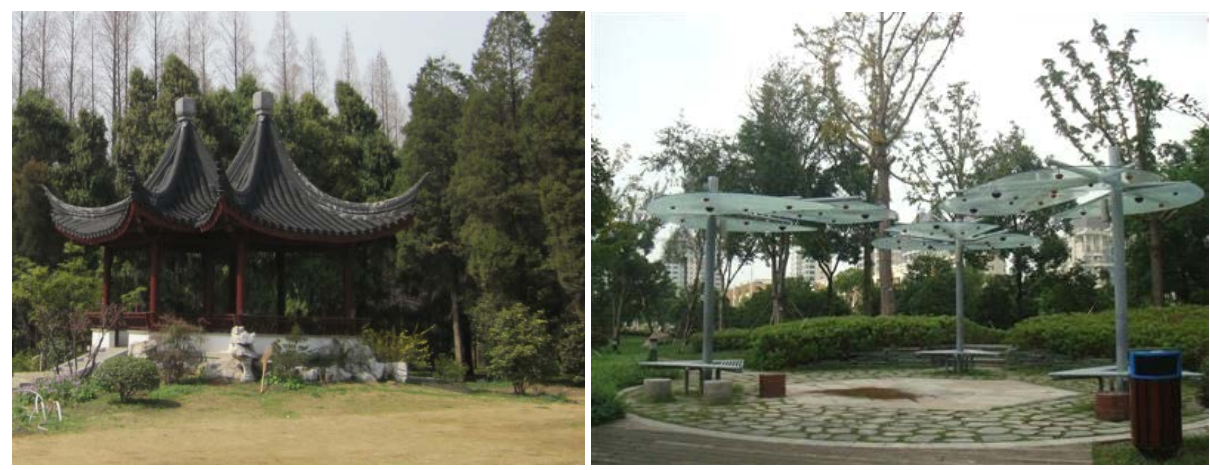

Figure 5. Translucent material landscape pavilion and opaque material landscape pavilion.
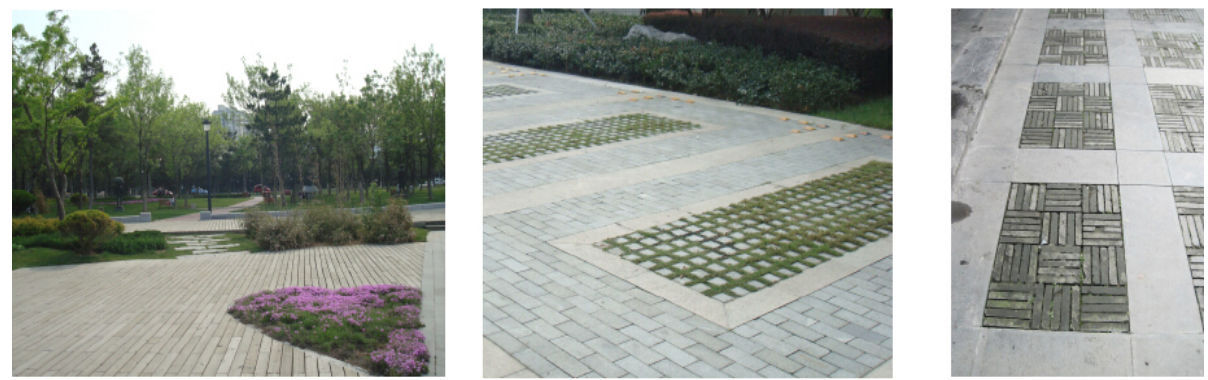

Figure 6. Rigid pavement combined planting, Grass brick inlay and different combinations of pavement.

can effectively improve the regional climate.

In winter, it is the climate environment in the landscape space. Compared with the natural ventilation design in summer, winter needs more regional wind invasion. Effective wind control can increase the comfort of people in the environment.

In summary, the landscape facilities through different materials and design of the facilities can effectively on the solar radiation, air temperature and humidity, wind environment impact. Landscape facilities design of urban landscape space should be integrated landscape facilities for the design of spatial and climatic factors [20].

\section{Conclusions}

There is such a hypothetical example, showing the influence of climate on landscape design: the tropical desert with a parapet around the courtyard allows the user had a completely different psychological feeling. Completely enclosure wall design secures that the wind cannot enter the building, the use of dark walls of paint absorbs the amount of solar radiation, the ground and the pavement with a thick enough cement increases heat radiation, and heat gathers up. Imagining in such a courtyard to enjoy the leisure time in the afternoon is a kind of suffering. Conversely, in the same place and climate conditions, it can also create a cool and pleasant garden environment. In the design process of both sides of the heightening walls, as far as possible into every trace of breeze, walls with blue gray stone and rough surface can reflect heat and climbing plants. In the courtyard with a pool design, scattered fountain can not only make water in air, reducing the temperature, but also can infiltrate sunken planting beds. Plant can be selected as umbrella tree, in beds formed in the shade, rattan tables and chairs placed under it do not have a taste. This is an example of two extremes, with a different design approach to show the impact of climate on landscape design.

The impact of climate is deep in every corner of the landscape design, the design process of rational use of climate characteristics should adapt to the nature and to get the harmony between man and nature landscape effect. Moreover, recommendation that mainly focuses on landscape facilities/construction and material selection can help designers identify the different function in different climate when choosing same type of material. Based on conclusion, landscape characters, achievement and relevant knowledge could increase the multifunction use in the further design concept, such as site survey and analysis on topography; waterscape evaluation; 
and ground material application. Due to the lack of specific case studies (limited by many global types), practical design process should follow its unique circumstance.

\section{References}

[1] Biddulph, M. (2010) Liverpool 2008: Liverpool’s Vision and the Decade of Cranes. In: Punter, J., Ed., Urban Design and the British Urban Renaissance, Routledge, Abingdon, 100-114.

[2] Bond, S. (2011) Assessment of the Potential Impact of the Proposed Liverpool Waters Master Plan on OUV at Liverpool Maritime Mercantile WHS for English Heritage. Heritage Places, Dulverton, Somerset.

[3] Hradsky, R. (2009) Triumph, Disaster and Decay: The SAVE survey of Liverpool's Heritage. SAVE Britain's Heritage, London.

[4] (2015) Design with Climate: Bioclimatic Approach to Architectural Regionalism. Princeton University Press, Princeton, 2-4.

[5] Hughes, Q. (1964) Seaport: Architecture \& Townscape in Liverpool. Lund Humphries, London.

[6] Hunter, M. (2011) Using Ecological Theory to Guide Urban Planting Design: An Adaptation Strategy for Climate Change. Landscape Journal, 30, 173-193. http://dx.doi.org/10.3368/lj.30.2.173

[7] Jiang, F. and Zheng, Y. (2014) Based on the Urban Waterfront Landscape Image of the Waterfront Place Design. AMM, 496-500, 2435-2438. http://dx.doi.org/10.4028/www.scientific.net/AMM.496-500.2435

[8] Beckett, J. (2011) Topography and Landscape History: The Role of the Victoria County History. Landscape History, 32, 57-65. http://dx.doi.org/10.1080/01433768.2011.10594659

[9] Pendlebury, J. (2009) Conservation in the Age of Consensus. Routledge, London.

[10] Rodwell, D. (2008) Urban Regeneration and the Management of Change: Liverpool and the Historic Urban Landscape. Journal of Architectural Conservation, 14, 83-106. http://dx.doi.org/10.1080/13556207.2008.10785025

[11] Pielke, R.A., Marland, G., Betts, R.A., Chase, T.N., Eastman, J.L., Niles, J.O. and Running, S.W. (2002). The Influence of Land-Use Change and Landscape Dynamics on the Climate System: Relevance to Climate-Change Policy beyond the Radiative Effect of Greenhouse Gases. Philosophical Transactions of the Royal Society of London A: Mathematical, Physical and Engineering Sciences, 360, 1705-1719.

[12] Pearson, R.G. and Dawson, T.P. (2003) Predicting the Impacts of Climate Change on the Distribution of Species: Are Bioclimate Envelope Models Useful? Global Ecology and Biogeography, 12, 361-371. http://dx.doi.org/10.1046/j.1466-822X.2003.00042.x

[13] Nasir, R., Ahmad, S. and Ahmed, A. (2013) Physical Activity and Human Comfort Correlation in an Urban Park in Hot and Humid Conditions. Procedia-Social and Behavioral Sciences, 105, 598-609. http://dx.doi.org/10.1016/j.sbspro.2013.11.063

[14] Theurillat, J.P. and Guisan, A. (2001) Potential Impact of Climate Change on Vegetation in the European Alps: A Review. Climatic Change, 50, 77-109. http://dx.doi.org/10.1023/A:1010632015572

[15] Sheppard, S.R. (2005) Landscape Visualisation and Climate Change: The Potential for Influencing Perceptions and BEhaviour. Environmental Science \& Policy, 8, 637-654. http://dx.doi.org/10.1016/j.envsci.2005.08.002

[16] Mahmoud, A. (2011) Analysis of the Microclimatic and Human Comfort Conditions in an Urban Park in Hot and Arid Regions. Building and Environment, 46, 2641-2656. http://dx.doi.org/10.1016/j.buildenv.2011.06.025

[17] Pan, F. (2013) Modern Urban Ecological Waterscape Planning and Design. AMR, 689, 505-508. http://dx.doi.org/10.4028/www.scientific.net/AMR.689.505

[18] Hinzman, L.D., Bettez, N.D., Bolton, W.R., et al. (2005) Evidence and Implications of Recent Climate Change in Northern Alaska and Other Arctic Regions. Climatic Change, 72, 251-298. http://dx.doi.org/10.1007/s10584-005-5352-2

[19] Shahidan, M., Jones, P., Gwilliam, J. and Salleh, E. (2012) An Evaluation of Outdoor and Building Environment Cooling Achieved through Combination Modification of Trees with Ground Materials. Building and Environment, 58, 245-257. http://dx.doi.org/10.1016/j.buildenv.2012.07.012

[20] Wu, X. and Peng, Z. (2012) Use of Waste-Material Selection in Landscape Design. AMM, 174-177, $2626-2631$. http://dx.doi.org/10.4028/www.scientific.net/AMM.174-177.2626 


\section{Submit or recommend next manuscript to SCIRP and we will provide best service for you:}

Accepting pre-submission inquiries through Email, Facebook, LinkedIn, Twitter, etc.

A wide selection of journals (inclusive of 9 subjects, more than 200 journals)

Providing 24-hour high-quality service

User-friendly online submission system

Fair and swift peer-review system

Efficient typesetting and proofreading procedure

Display of the result of downloads and visits, as well as the number of cited articles

Maximum dissemination of your research work

Submit your manuscript at: http://papersubmission.scirp.org/ 